\title{
FLUJOS, REDES MIGRATORIAS E INSERCIÓN LABORAL. LA MIGRACIÓN CHILENA EN USHUAIA, 1947-1970
}

LAURA HORLENT

\section{RESUMEN}

La ciudad de Ushuaia debe su crecimiento al aporte constante de migrantes tanto nacionales como extranjeros. El presente trabajo se focaliza en los migrantes de origen chileno que arribaron a la ciudad entre 1947 y 1970 y que constituyeron durante muchos años la mayor parte de la población. Se analizan, por un lado, las características económicas de la región y las políticas estatales de fomento poblacional para observar su interrelación con los circuitos y flujos migratorios regionales. Paralelamente, y a través del análisis de entrevistas a migrantes de origen chileno, se analizaron las redes migratorias y las trayectorias de quienes se radicaron en Ushuaia así como las posibilidades y condiciones de su inserción laboral.

PALABRAS CLAVE: migrantes chilenos, redes migratorias, Ushuaia, Tierra del Fuego.

\section{FLOWS, MIGRANT NETWORKS AND LABOR MARKET INTEGRATION. CHILEAN MIGRATION IN USHUAIA, 1947-1970}

\begin{abstract}
Ushuaia's population has grown due to a steady national and foreign migration. This paper focuses on the Chilean migrants who arrived in Ushuaia between 1947 and 1970, and who made up the majority of the local population for many years. Firstly, the economic features of the area and the governmental policies to encourage population are analyzed to examine their interrelation with the regional migration routes and flows. On the other hand, the migrant networks and the trajectories of those who settled down in Ushuaia, as well as their labor-market integration are analyzed through interviews to these Chilean migrants.
\end{abstract}

KEY WORDS: Chilean migrants, migrant networks, Ushuaia, Tierra del Fuego. 


\section{INTRODUCCIÓN}

La ciudad de Ushuaia debe su crecimiento al aporte constante, a lo largo de su historia, de migrantes tanto nacionales como extranjeros. Aunque el flujo de migrantes nunca se detuvo, alcanzó algunos picos notables en determinados periodos, por lo general, al calor de políticas nacionales dirigidas a consolidar la presencia argentina en la región. El presente trabajo se focaliza en los años que van desde 1947, fecha en que se cierra el penal que había constituido el motor del primer crecimiento de la ciudad, hasta 1970 aproximadamente, década durante la cual se sancionó y comenzó a implementarse la ley 19.640 que le dio impulso a la actividad industrial y cuyo efecto más notorio fue un crecimiento poblacional explosivo durante los años '80. El periodo que consideramos aquí es menos espectacular que el que le siguió y ha sido menos estudiado. En su transcurso la ciudad creció de manera moderada pero sostenida, disminuyendo el porcentaje de migrantes europeos en favor de los oriundos de países limítrofes y de los argentinos provenientes de diferentes provincias. De entre quienes se radicaron en ella durante estos años, los nacidos en Chile constituyeron el grupo más numeroso. Aun hoy conforman el porcentaje mayoritario de lo que se denomina antiguos pobladores, categoría social difusa pero de fuerte peso simbólico que identifica genéricamente a aquellas personas nacidas o arribadas a la isla de Tierra del Fuego antes de la implementación de la mencionada ley de promoción industrial.

El presente trabajo se basa en el análisis de entrevistas a estos antiguos pobladores. Fueron entrevistados alrededor de 30 migrantes de origen chileno, la mayor parte de ellos arribados a Ushuaia entre los años de 1947 y $1970^{1}$.

Se aborda este análisis a partir de una hipótesis general que sostiene que el crecimiento de un centro poblado como Ushuaia en el extremo sur del país adquiere las características que lo distinguen a partir de la particular dinámica de interrelación entre una política estatal específica de fomento poblacional y la existencia de circuitos migratorios regionales transnacionales previamente constituidos. El objetivo general de este trabajo es aproximarnos al análisis de esta dinámica indagando en las características de los flujos migratorios y las posibilidades de inserción laboral en Ushuaia. Para ello se ha buscado, en primer lugar, caracterizar los flujos migratorios a partir de los cuales fue creciendo la ciudad durante el periodo de referencia analizando las condiciones económicas, sociales y políticas generales que los posibilitaron. En segundo término, se analizaron las redes migratorias y las trayectorias de quienes se radicaron en Ushuaia así como las modalidades de su inserción laboral, entendiendo que la oferta de trabajo que realizaron diversos entes estatales argentinos fue un elemento clave para efectivizar una política de atracción poblacional.

\section{Antecedentes}

Entre los estudios relevados sobre la población de Ushuaia entre 1947 y 1970 encontramos, por un lado, un conjunto breve pero significativo de trabajos de análisis estadístico en base a información censal. El primero de ellos es una tesis de licenciatura en Geografía que analiza la estructura poblacional de Tierra del Fuego (Liberali, 1978). Los otros trabajos son más recientes y analizan diversos aspectos de las migraciones -vinculación con la estructura social, procesos de formación de la fuerza laboral, etc. durante la década del '90 (Carpinetti, 2003) y durante la del 2000 hasta la actualidad (Dir. Gral. de Estadística y Censos [DGEyC] 2014; Varela, 2015; Farías \& López, 2016). Estos últimos pese
1 Las entrevistas se realizaron en el marco de un Proyecto de Archivo de Memoria Oral llevado adelante por la Dirección de Administración y Gestión del Patrimonio Histórico Cultural de la Municipalidad de Ushuaia. Durante su transcurso se realizaron alrededor de 60 entrevistas. Los entrevistados fueron, en su gran mayoría, seleccionados aleatoriamente de un padrón general de antiguos pobladores confeccionado por la Comisión de Pioneros y Antiguos Pobladores de Ushuaia de carácter autónomo aunque apadrinada por la Municipalidad de Ushuaia. Un porcentaje menor de entrevistados fue contactado a partir de las referencias de otros entrevistados siguiendo el método "bola de nieve". Del conjunto de entrevistas se seleccionaron unas 30 para ser analizadas con más profundidad en función de los propósitos de este trabajo. La investigación también abarcó observaciones en terreno de reuniones de antiguos pobladores en Ushuaia y de los Encuentros binacionales de antiguos pobladores del 2014 y 2015. 
a centrarse en los últimos años, contienen útiles referencias al proceso histórico. Para los propósitos de este trabajo, el antecedente más importante es el trabajo del sociólogo José Luis de Imaz publicado en 1972 con el nombre de Los hombres del confín del mundo. Con el objeto de analizar la estructura social de Tierra del Fuego, de Imaz realizó en 1970 un trabajo de campo de tres meses en el que entrevistó a numerosas personas además de recopilar diversos tipos de documentación local que le proporcionaron una amplia base para su investigación. En lo que se refiere a la migración chilena, de Imaz analizó una muestra de prontuarios policiales que, cabe señalar, no estaban referidos a la comisión de delitos sino que constituian un expediente informativo para iniciar, por ejemplo, trámites de radicación. La información recabada - lugar de origen de los migrantes, niveles educativos, objetivos, ocupaciones y profesiones al ingresar al país, características de su medio ambiente familiar, etc.- constituye para nosotros una invalorable referencia para contrastar la información que surge de la memoria de algunos de estos migrantes 45, 50, o incluso, 60 años más tarde. Además de lo referido estrictamente a los migrantes, resulta de notable valor el análisis del conjunto de la sociedad fueguina y sus consideraciones sobre la estratificación social.

Por otrolado, hemos consultado trabajos que abordan nuestro caso como parte de perspectivas más generales -espaciales y/o temporales- o bien refiriéndose a otros movimientos migratorios, entre ellos destacan los de Torres (2001), Ceva (2006), Lattes (2007) y Mallimaci (2012). Existen, también, algunos trabajos recientes que indagan en la relación entre migraciones, formación de representaciones sociales y procesos identitarios (Mallimaci, 2011) Hermida (2013), aunque analizan fenómenos actuales, ubican sus raíces en procesos de más larga duración. Por último, mencionaremos algunos trabajos generales sobre la historia y economía de la Tierra del Fuego argentina (Luiz \& Schillat, 1998; Mastroscello, 2009) aunque no abordan en detalle las migraciones chilenas.

\section{El concepto de red migratoria}

Para abordar el presente caso hemos recurrido, principalmente, al concepto de red migra- toria. Conviene, entonces, señalar brevemente qué se entiende por red migratoria. Desde hace varias décadas la noción de red migratoria -o también red social- desempeña un papel central en la investigación y explicación de las migraciones y dio lugar a una variada profusión de conceptos y perspectivas que se desprenden de ella (Arango, 2003; Hily et al. 2004; Massey \& Aysa-Lastra, 2005; Pedone, 2010). En términos generales las redes migratorias pueden definirse como conjuntos de relaciones interpersonales que vinculan a los inmigrantes, a emigrantes retornados o a candidatos a la emigración con parientes, amigos o compatriotas, ya sea en el país de origen o en el de destino. A través de las redes se transmite información, se proporciona ayuda económica o alojamiento y se presta apoyo a los migrantes logrando así la reducción de la incertidumbre y los costos que acompañan a la migración (Arango, 2003). Se ha considerado que las redes constituyen una forma de capital social y que quienes cuentan con ellas mejoran su experiencia migratoria en múltiples aspectos a la vez que tienen más probabilidades de emprender una migración internacional (Massey \& Aysa-Lastra, 2005). En esta perspectiva las redes migratorias han sido puestas en un primer plano para la explicación de las causas de la migración, postulándose, incluso, que constituyen un fenómeno autosostenido y autoperpetuador. Esta perspectiva, conocida como causalidad acumulativa, ha llamado la atención sobre diversos factores y mecanismos que generan nuevas migraciones a partir de migraciones previas (Arango, 2003; Massey \& Aysa-Lastra, 2005). En otros abordajes se ha llamado la atención sobre el papel que las redes cumplen en la sociedad receptora. En estos casos se ha subrayado que las redes fortalecen los lazos comunitarios de los migrantes en el nuevo destino pero también se ha planteado cómo estas redes posibilitan la integración en la sociedad receptora, al constituirse en ámbitos de interacción con aquélla (Hily et al. 2004).

En el caso que analizamos, consideramos que estas redes migratorias han tenido una importante incidencia en las características que tuvieron las migraciones a Ushuaia en varios aspectos. Como estamos tomando un periodo en el que la migración no es pionera, es decir, 
no se trata de los primeros chilenos que llegan a la región, por un lado, y, por el otro, quienes migran provienen de una región con amplia experiencia en la emigración era esperable encontrar estas redes ya en funcionamiento y consolidadas (Torres, 2001; Mallimaci, 2012). Ligamos, entonces, las redes migratorias con lo que describiremos más adelante como una cultura de la migración: aquéllas como el soporte material de un tipo de percepción y de práctica. Sostendremos, también, que la red migratoria constituyó un mediador necesario para articular un tipo de economía vinculada al mercado mundial -con su propia lógica de circulación de capital y trabajo y su dinámica de atracción de trabajadores- con el propósito del Estado argentino de fomentar la población de un punto específico de su territorio a partir de una consideración de orden geopolítico.

\section{LA POBLACIÓN DE USHUAIA ENTRE 1947 Y 1970}

¿De qué magnitudes de población estamos hablando? Las cifras no son muy impresionantes: después de más de 60 años de establecida la Subprefectura de Ushuaia, acto que se considera fundacional de la ciudad, la población apenas sobrepasaba las 2.000 personas. Precisamente en ese año de 1947 en que se cerraba el Presidio y Cárcel de Reincidentes, institución central y primer motor del crecimiento de la localidad, se realizó un Censo Nacional que nos permite conocer la cantidad y la conformación de la población de Ushuaia. Dicho censo arrojó la cifra de 5.045 habitantes para toda la isla de Tierra del Fuego; de ellos, unos 2.182 habitantes correspondían al Departamento Ushuaia. En 1970, al final del periodo que hemos abarcado en el análisis, la población total de la isla ascendía a 13.527 habitantes y la del Departamento Ushuaia a 5.700. El crecimiento acumulado en el periodo elevó la población a más del doble. Ese incremento no se debió, en principio, al crecimiento vegetativo puesto que un rasgo característico durante este periodo fue el elevado índice de masculinidad que partió de 269 hombres por cada 100 mujeres en 1947 llegando a 172,8 en 1970. Estos índices señalan dificultades para contraer matrimonio y arraigarse, de lo que deriva un crecimiento vegetativo menor que en poblaciones equilibradas y un índice de emigración alto (Liberali, 1978).

Uno de los rasgos más notables de la población de la isla de Tierra del Fuego durante el periodo considerado fue el elevado índice de extranjeros que la componían, no obstante constituir ésta una tendencia decreciente (ver Tabla 1). Así, el censo de 1947, registró un $59 \%$ de extranjeros y el de 1970 casi un $39 \%$. Estas cifras, sin embargo, son más elevadas si se tienen en cuenta algunos detalles: al considerar solamente a las personas en edad activa el porcentaje de extranjeros era de un $70 \%$ en

Tabla 1. Población según Censo por lugar de nacimiento. Absolutos y relativos. Tierra del Fuego. Años 1895 a 1970.

\begin{tabular}{|c|c|c|c|c|c|}
\hline Censos Nacionales & $\begin{array}{c}\text { Población } \\
\text { Tierra del Fuego }\end{array}$ & $\begin{array}{l}\text { Lugar de } \\
\text { nacimiento } \\
\text { (absolutos) }\end{array}$ & & $\begin{array}{l}\text { Lugar de } \\
\text { nacimiento } \\
\text { (relativos) }\end{array}$ & \\
\hline & & En el país & En el extranjero & En el país & En el extranjero \\
\hline 1895 & 477 & - & - & - & - \\
\hline 1914 & 2.504 & 927 & 1.577 & 37,0 & 63,0 \\
\hline 1947 & 5.045 & 2.061 & 2.984 & 40,9 & 59,1 \\
\hline 1960 & 7.955 & 4.236 & 3.719 & 53,2 & 46,8 \\
\hline 1970 & 13.527 & 8.296 & 5.231 & 61,3 & 38,7 \\
\hline
\end{tabular}

Fuente: Tomado de DGEyC. Provincia de Tierra del Fuego. (marzo 2014) Serie de Análisis Social: Migración y empleo en Tierra del Fuego 3. Ushuaia. 
1947 y de un $50 \%$ en 1970 (Liberali, 1978) 2.

Tal como lo indican las cifras, la población de Tierra del Fuego fue aumentando y ello debe atribuirse a un saldo migratorio favorable. Los migrantes fueron tanto argentinos como extranjeros pero éstos últimos constituyeron el aporte más sustancial. El censo de 1947 indicaba que, de entre los extranjeros que habitaban en Ushuaia, el $60 \%$ era de origen sudamericano. Como en este censo los orígenes se consignaron por continente, separando los provenientes de América del Norte y los de América del Sur, no es posible contar con el dato preciso de la cantidad de chilenos que participaban en ese conjunto de sudamericanos pero con alta probabilidad se trataba de la mayoría. Ello se confirma indirectamente con la casi inexistencia, en la actualidad, de antiguos pobladores sudamericanos que no sean chilenos. La proporción de chilenos, dentro del conjunto de migrantes extranjeros, fue aumentando notablemente tal como se desprende del censo territorial realizado en 1966: allí aparecen como la casi absoluta mayoría de los migrantes extranjeros. En efecto, los chilenos representaban el $39 \%$ de la población total mientras un 3\% más reunía al resto de los extranjeros para constituir, en conjunto, el $42 \%$ de la población total (Liberali, 1978).

\section{LAS MIGRACIONES}

\section{Circuitos migratorios regionales}

La Patagonia constituyó, desde fines del siglo XIX, un polo de atracción para migrantes provenientes tanto de Europa como de América del Sur. Un acelerado desarrollo económico, el perfil capitalista y altamente integrado de la región y algunas políticas estatales más específicas de fomento poblacional promovieron el ingreso

2 Otro detalle señalado por Liberali (1978) es que el porcentaje de extranjeros en la edad pasiva definitiva, es decir el de las personas mayores, fue, durante esos años, estable y mucho más elevado que el correspondiente a las edades activas, indicando así que los migrantes de origen extranjero solían radicarse definitivamente y los de origen argentino retornaban a sus lugares de origen en edades avanzadas. Por otro lado, la autora también señala la presencia de un porcentaje de extranjeros no registrados como radicados, aquellos que se encontraban en el país sin la documentación necesaria y que aparecían como infractores de las leyes sostenido de trabajadores generándose movimientos migratorios intensos y fluidos. Analizaremos a continuación, con más detalle, las características de estos movimientos migratorios centrándonos en los que tuvieron lugar entre Argentina y Chile.

Aunque la migración chilena a la Argentina -que ya aparece consignada en el Censo Nacional de 1895- también se dirigió a otras regiones, el mayor número de migrantes se concentró en la Patagonia. Los flujos más numerosos corresponden al periodo de implementación de la política de sustitución de importaciones (19301970) prolongándose hasta mediados de los años '90 (Ceva, 2006; Gobantes et al. 2011). Una observación que se ha hecho es que, en cada zona de la Patagonia, han predominado -y predominanmigrantes de unas determinadas regiones de Chile, por lo general, las contiguas a la región de emigración. Así, en la Patagonia austral (Chubut, Santa Cruz, Tierra del Fuego), la mayoría provenía de las regiones fronterizas de Aysén y Magallanes. El detalle relevante aquí es que estas dos regiones chilenas habían recibido, a su vez, una alta tasa de migrantes internos, especialmente de la Provincia de Chiloé (región de Los Lagos). De tal manera que, aunque los migrantes entraran a Tierra del Fuego procedentes, por caso, de Punta Arenas, como era lo habitual, solían ser oriundos de mucho más al norte (Gobantes et al. 2011). Las entrevistas realizadas por nosotros reflejan, previsiblemente, esta imagen: en su enorme mayoría los migrantes chilenos en Ushuaia son originarios de Chiloé. Muchos de los entrevistados señalaron como lugar de origen a diversas comunidades rurales de Chiloé (Linao, Queilén, Achao, Tenaun, etc.) o, en otros casos, parajes rurales cercanos a Puerto Montt como, por citar un ejemplo, Mesquihué.

Chiloé aparece, entonces, como el punto inicial de muchas trayectorias migratorias. $\mathrm{Si}$

nacionales (Liberali, 1978).

3 Así lo había consignado también de Imaz (1972) quien, sobre una muestra de 470 casos de migrantes chilenos, encontró que el $60 \%$ eran nacidos en Chiloé, un $20 \%$ en el Valle Central Sur y otro $20 \%$ aproximadamente en Magallanes. Como los provenientes del Valle Central Sur, lo eran principalmente de Llanquihue, que es aledaño a Chiloé, y que, junto con los provenientes de Magallanes, podian con alta probabilidad ser de origen chilote, concluía que la amplia mayoría de quienes habían ingresado a Tierra del Fuego provenían de Chiloé. 
Tabla 2. Población de la Provincia de Chiloé, urbana y rural según censos de 1940, 1952, 1960 y 1970.

\begin{tabular}{lcccc}
\hline Provincia de Chiloé & Censo de 1940 & Censo de 1952 & Censo de 1960 & Censo de 1970 \\
\hline Población total & 101.706 & 100.687 & 99.211 & 111.194 \\
Población Urbana & 12.675 & 18.096 & 21.956 & - \\
Población Rural & 89.031 & 82.591 & 77.255 & - \\
\hline
\end{tabular}

Fuente: Elaboración propia en base a datos tomados de DGEyC. Censo de Chile 1960 e INE. Población. Total país 1970.

Nota: no se ha podido recuperar el dato de la población rural y urbana desagregado por provincia para 1970.

focalizamos la vista allí podremos observar que esa región sufrió, durante este periodo, una notable disminución de su población.

Como puede observarse en la Tabla 2 la población de Chiloé disminuyó progresivamente entre 1940 y 1960, deteniéndose esta tendencia hacia 1970. Para tener una referencia de la peculiaridad de este movimiento, hay que señalar que la población total de Chile aumentó de, aproximadamente, unos 5 millones de habitantes en 1940 a unos 8,8 millones en 1970 (DGEyC, Censo, 1960; INE, Censo, 1970). Según Gobantes et al. Desde fines del siglo XIX hasta la década de 1980, más del 50\% de la población nacida en la Provincia de Chiloé se empleó temporal o definitivamente en mano de obra no calificada, localizadas en la Patagonia Austral chilena y argentina (2011, p. 1). Es decir, que la disminución de su población debe atribuirse a estas impactantes tasas de emigración. Las razones que han esgrimido algunos investigadores para explicar semejante flujo de personas remiten en primer lugar al diferente desarrollo de las economías regionales. Consideran necesario ponderar el atraso económico de Chiloé respecto de otras provincias chilenas, y marcadamente respecto de Magallanes, la región en la que se encuentra Punta Arenas. Contribuyendo a este proceso, la acción del Estado chileno se orientó, durante esos años, a la promoción de zonas nuevas como la Patagonia en detrimento de otras como Chiloé (De La Calle, 1989; Lausic, 2005, Gobantes et al. 2011). Por las mismas razones de desigual desarrollo regional se explica el paso a la Argentina, recordando que los lados argentino

4 Para tener una referencia puede mencionarse que, según datos del Censo de 1960, la población urbana de Chiloé era de apenas el $22 \%$ del total, la más baja de todo Chile. Más de dos tercios de la población mayor de 12 años económicamente activa estaba ocupada en la agricultura y chileno habían funcionado, en el extremo sur, como una unidad económica durante la primera mitad del siglo XX. Esto, sin embargo, iría cambiando hacia mediados del siglo.

La economía de Chiloé estaba, efectivamente, apoyada en una agricultura de pequeños propietarios minifundistas que, por lo general, cultivaban papa o trigo y tenían algo de ganado, complementando su sustento con algunas actividades de pesca artesanal o trabajo de leñador ${ }^{4}$. Se trataba de una economía de autoconsumo en la que el trueque y algunos mecanismos de trabajo colaborativo cumplían un papel importante. En ese escenario el acceso al ingreso monetario presentaba dificultades y la migración se constituía en una posibilidad de obtenerlo. Estos propietarios, al migrar, se convertían en jornaleros pero accedían así a salarios en metálico (Gobantes et al. 2011; Lausic, 2005).

En las entrevistas realizadas esta situación aparece recurrentemente manifestada.

Teníamos una propiedad muy grande y después vendimos una parte de eso, del campo, a $6 \mathrm{~km}$. del pueblo y nos fuimos a vivir... [al pueblo] Mi papá era agricultor de campo, sembraba, vendía, tenía animales, cosas así, todo lo que se hacía en el campo. [...] Cuando yo bajé al pueblo ya tenía 5 o 6 años [...] Allá mi finada mamá compró una casa, que allá todos los terrenos son inmensos de grandes, tenía 180 de fondo por 40 de frente, asi que ahí viviamos, ahi se sembraba todo, porque se

y pesca, siguiéndole en importancia los artesanos y operarios, luego los obreros y jornaleros y, por último, los trabajadores empleados en servicios personales (DGEyC, Censo Población, 1960). 
da todo, habas, arveja, porotos, se da la manzana, la pera [...] vendió una parte mi mamá [del campo], la otra parte teníamos 3, 4 animales todavía ahí, que nosotros íbamos a verlos con mi hermano, ya éramos más o menos grandes, de 10, 12 años (Sergio, llegado a Ushuaia en 1952).

Como se puede observar en este caso se trata de pequeños propietarios de la tierra (primero de un campo, luego cuando el padre de la familia fallece, de un terreno más pequeño pero situado en el pueblo) que cultivan y crían algunos animales pero no les alcanza para la subsistencia. En otro pasaje de la entrevista Sergio señaló que, para ese momento, dos de sus hermanas mayores se encontraban empleadas como servicio doméstico en la ciudad de Castro y que un hermano mayor les enviaba dinero regularmente desde Tierra del Fuego que obtenía como empleado en una estancia del lado chileno de la isla, primero, y como empleado en un aserradero en Ushuaia, más tarde.

En alguno de los casos el entrevistado describió su situación en Chiloé, en términos que intentaban darle un poco de brillo a la situación pero sin poder ocultar del todo la pequeña escala en que se operaba: Yo allá era capataz de la pequeña estancia que había, era capataz con 16 años, y especialista en quesos (Enrique, llegado a Ushuaia en 1947).

La fragilidad de estas situaciones se hacía manifiesta frente a cualquier circunstancia adversa, tal como se ve en el siguiente testimonio:

Mi padre era colono, en San Pedro, la zona de Castro, afuera en el campo, cercano a un río que ahora no recuerdo el nombre, alli nos fuimos a vivir, una casita humilde. Mi padre tenía animales: vacunos, caballares. Y un gran deshielo del río que pasaba al lado de la casa, una noche barrió con todo. Una gran creciente llevó puentes, llevó todo. Mi padre perdió los animales, perdió la casa, apenas nos salvamos nosotros porque estábamos cerca de una loma. Alli decide mi padre venirse a la Argentina, yo ya estaba nacido, en el '46 más o menos... (Juan, llegado a Ushuaia en 1947).
De cualquier manera, el minifundio no podía dividirse ni sostener muchos hijos tal como lo señalaba otro entrevistado: en esos años había mucha escasez de trabajo en Chiloé y allá éramos muchos hermanos, éramos siete hermanos,... ¿qué íbamos a hacer todos en la casa? (Tomás, llegado a Ushuaia en 1948).

\section{Migrar como recurso}

Tasas de emigración tan altas y sostenidas en el tiempo como las que se han señalado produjeron, por otro lado, lo que podría denominarse, muy genéricamente, una cultura de la migración, es decir, la incorporación de la migración como un recurso disponible y siempre presente para la reproducción individual o familiar (Mallimaci, 2012). Es lo que aparece implícito en la cita anterior: quedarse es una opción que requiere una razón, una justificación, caso contrario, lo lógico es partir (¿qué íbamos a hacer todos en la casa?). O como aparece en la definición que hace un entrevistado de su propia familia: la suya es una familia de migrantes.

Nací en Chiloé, Chile. Somos de una ascendencia francesa, [...] de una migración francesa que se instaló en el archipiélago de Chiloé. [...] Pero como es una familia de migrantes, nunca se quedan en un lugar, salieron todos cuando las cosas se dieron en otro lugar. Mi padre estuvo en la Patagonia en el desastre de la Patagonia cuando se mataba a la gente. En aquellos años él estuvo y él se salvó con otro. Y él dijo: yo nunca más salgo de este rincón. Resulta... ¿qué pasó? Salieron sus hijos y sus nietos (Francisco, llegado a Ushuaia en 1952).

Otra manifestación de esta misma cuestión es el de la familiaridad, desde la infancia, con la experiencia de la migración de otros.

...mire lo que es cuando uno es chico, cuando yo allá me conversaban de Tierra del Fuego yo pensaba que era porque había mucho calor. Yo decía, ¿será que hay más calor que acá? [...] por algo le 
dicen Tierra del Fuego.. [...].

Pregunta-¿¿Y allá se hablaba...?

Respuesta -Claro, allá se sabía porque mucha gente de Chiloé se venía a trabajar acá, toda la gente que trabajaba en las estancias, eran de allá, de esos lugares de Chiloé, entonces todos llegaban con bombachas, como criollos, decían estamos en Tierra del Fuego. Para nosotros..., escuchábamos, como éramos chicos nos llamaba la atención... (Mary, llegada a Ushuaia en 1967).

Abonando este mismo argumento, Gobantes et al. han señalado, en su investigación sobre los emigrantes de Chiloé, que la constitución de un imaginario complejo en el que se mezclan la mitología, el paso a la adultez, el prestigio y el ideal errante del viajero (2011, p. 18) desempeñó un rol fundamental en las decisiones que impulsaron el viaje de los chilotes.

\section{Itinerarios y redes}

Como ya hemos señalado, una gran parte de esos emigrantes de Chiloé se dirigieron a la Patagonia chilena y argentina. En lo que atañe a quienes llegaron y luego se quedaron en Tierra del Fuego y Ushuaia registramos, a partir de las entrevistas realizadas, algunos itinerarios recurrentes con una primera estación en Punta Arenas y de allí a otros puntos de la región. El perfil de los emigrantes también presenta algunas características regulares. Por un lado, el conjunto más numeroso de migrantes corresponde a hombres, muchos de ellos bastante jóvenes (16, 17 años) y solteros, en menor medida de mayor edad y casados ${ }^{5}$. Luego aparecen migraciones de grupos familiares que vienen a reunirse con el hombre migrante ya instalado en la región, como

5 Esta caracterización de los perfiles migrantes debe tomarse, lógicamente, como un indicador que requeriría ser contrastado con otras fuentes, puesto que se elabora a partir de la información provista por nuestros entrevistados sobre ellos mismos y sus allegados y es necesario tener en cuenta varios sesgos, entre ellos, el de la edad de nuestros entrevistados: quienes llegaron, durante el periodo considerado, a edades más altas, presumiblemente, ya han fallecido. Sin embargo, coincidentemente, Gobantes et al. (2011) señalan que la edad habitual para el primer viaje de es el caso de las esposas o futuras esposas, de los hijos o también de la madre y hermanos pequeños del migrante. En último lugar aparece un grupo pequeño de mujeres jóvenes y solteras.

En el caso del primer grupo mencionado, el de los jóvenes varones que arribaban a Punta Arenas, el itinerario los llevaba a las estancias de Puerto Natales, Santa Cruz o Tierra del Fuego para incorporarse como peones a las tareas rurales. Estos trabajos podían durar una sola temporada o varios años pero solía ocurrir que dieran paso a nuevos movimientos hacia otras estancias u obrajes o a los pequeños pueblos de la región ${ }^{6}$. El caso de Tomás da cuenta de esos movimientos. Tomás dejó Chiloé, en 1944, cuando contaba con 17 años. Se dirigió a la zona del Turbio, en Santa Cruz, para trabajar en una estancia donde ya trabajaba su hermano mayor. Un par de años después volvió a Punta Arenas a cumplir con el servicio militar. Una vez cumplido éste, retornó a Santa Cruz a emplearse en otra estancia. Unos pocos años después se dirigió a Ushuaia donde otros parientes le habían informado de la posibilidad de encontrar trabajo y le dieron un primer alojamiento. En el caso de Francisco se puede observar un ejemplo de desplazamiento en grupo familiar que se realiza entre centros poblados. Había nacido en Chiloé y fue traído de niño por su tía, primero a Punta Arenas y luego a Ushuaia donde permanecieron unos 2 años. Volvieron a Punta Arenas y un tiempo más tarde Francisco regresó a Ushuaia, ahora con su madre, padrastro y hermanos, recientemente llegados de Chiloé. Después de unos años en Ushuaia -y ya adulto- se dirigió a Río Gallegos donde tenía una prima y, de allí, a Comodoro Rivadavia, en donde vivían sus tíos. Unos años después vuelve a Ushuaia, llamado por su hermano.

Lo que queremos señalar es que tanto migrantes solos como en grupo familiar, unos y otros, aparecen recorriendo varias estaciones

los emigrantes chilotes era la de 16 años, momento en que ya se podía obtener un contrato de trabajo formal en las estancias.

6 Bascopé (2008) señala que la organización de la producción ovina en las estancias se había realizado asegurando la fluidez de los recursos y el personal que se necesitara. Mediante una serie de mecanismos se fomentaba la circulación de los trabajadores que las estancias sólo requerían para trabajos estacionales. 
regionales antes de radicarse definitivamente en Ushuaia. Solamente un entrevistado señaló que sus padres habian venido directamente de Chiloé a Ushuaia. La migración a Ushuaia solía ser, entonces, un segundo (o tercer o cuarto) movimiento si tomamos como inicio la salida de Chiloé, origen de la mayoría de los migrantes. Agreguemos también que esa ampliación del movimiento inicial podía ser generacional: padres emigrantes a Punta Arenas, hijos que se trasladan a Ushuaia. Estos datos son compatibles con las curvas de declinación de la economía magallánica, suave pero persistente, durante los años considerados (Martinic, 2002). Un ejemplo es el de Zoila, cuyo padre era de Castro, Chiloé. Ella llegó a Ushuaia en 1949 procedente de Punta Arenas porque... no había trabajo, estaba feo allá, yo trabajaba de mucama en casa de familia pero mi papá ya tampoco tenía trabajo. En ese sentido Ushuaia aparece como un destino satélite de los centrales que eran, o bien la propia ciudad de Punta Arenas o bien las grandes estancias ovinas de la región de la estepa (Natales, Santa Cruz y norte de Tierra del Fuego), al que se llegaba sólo si las cosas no resultan bien en estos destinos principales.

Varias observaciones se desprenden de los ejemplos expuestos. En primer lugar la fluidez de los movimientos. Además de las migraciones estacionales y las de retorno a Chiloé consignadas en la bibliografía (ver, por ejemplo, Gobantes et al. 2011) nuestros entrevistados también dan cuenta de una alta circulación regional. Sin mencionar el paso por diversas estancias, tanto de un lado como de otro de la frontera, encontramos que la mayoría había realizado las secuencias: Punta Arenas- Río Gallegos- Ushuaia o bien: Punta Arenas -Porvenir/ Río Grande - Ushuaia. El caso de Francisco que hemos mencionado con anterioridad es el único de nuestros entrevistados que incluyó un destino en la Patagonia norte (Comodoro Rivadavia). Los itinerarios que hemos relevado se restringían, por lo general, a la Patagonia Austral.

El otro elemento recurrente en los testimonios que hemos citado es que los desplazamientos se realizaban, en gran medida, a lugares en donde se podía encontrar parientes y conocidos. No tuvimos ningún caso en el que el migrante no hubiera señalado el contacto gracias al cual se decidió a llegar a Ushuaia. Como veremos, las redes migratorias se revelan como un elemento que interviene en la decisión de migrar, en la elección del destino, en la forma en qué se hace y en las posibilidades de inserción e integración en el lugar de llegada.

Las redes migratorias operan, entonces, en varios planos. Son, por ejemplo, las que median entre el migrante y el posible trabajo. En los testimonios citados más arriba se puede observar que a Tomás lo manda llamar su hermano para trabajar en una estancia. La misma situación de Sergio, otro entrevistado citado anteriormente, que es traído por un hermano que trabajaba en un aserradero cercano a Ushuaia. También los tíos aparecen llamando a sus sobrinos para que vengan a trabajar como el caso de Guillermo, llegado en 1951 a los 14 años, para incorporarse a la estancia José Menéndez en el norte de Tierra del Fuego. Este llamado era una forma frecuente de reclutamiento de nuevos trabajadores especialmente en el ámbito rural. Cuando se trataba de jóvenes que no habían cumplido la mayoría de edad, eran estos parientes los que autorizaban al menor.

Pero aun si no hay llamado y es el migrante el que toma la iniciativa del viaje, sigue siendo la red de parientes la que permite acceder al trabajo como se puede observar en el testimonio de Carlos, llegado a Río Grande en 1960. Allí lo recibe un primo de su madre que ... me tuvo ahi un par de días y fue él el que me consiguió Khami [trabajo en un aserradero en el lago Khami o Fagnano, distante $100 \mathrm{~km}$ de Río Grande], fue él el que me consiguió... o sea, me sacó de encima (risas).

La amplia red de parientes asentados en diversos puntos de la región permitía circular y aprovechar las oportunidades laborales que se presentaban en distintos lugares. Volviendo a los casos de Tomás y Francisco podemos ver que Tomás decide venir a Ushuaia, después de unos años trabajando en estancias de Santa Cruz porque otros parientes radicados en Ushuaia le han informado sobre la posibilidad de encontrar trabajo allí. En el caso de Francisco, luego de unos años en Ushuaia y en un momento de poco trabajo, se dirige a Río Gallegos, donde una prima le sugiere, a su vez, que vaya a Comodoro Rivadavia:

llegué a Comodoro a la casa de ese tío [...] me hizo pasar, me dio una 
pieza, [...], me dio un papelito, me fui a Jordan Cruz e hijos. ¿Qué sabés hacer?, me vio un hombre joven, 20 años... Te necesito ahora, vinieron los inspectores municipales, me sacaron Dni, yo no tenía documento... (Francisco, llegado a Ushuaia en 1952).

Nuevamente es el tío quien lo introduce y recomienda para un empleo en el que, además, le tramitan la documentación necesaria. Allí trabaja unos años hasta que decide volver a Ushuaia porque: me escribió mi hermano: estás perdiendo tu tiempo allá, Ushuaia cambió, hay trabajo...

Como se puede ver, a través de la red de parientes circula la información sobre oportunidades laborales pero, sobre todo, se ingresa al mercado laboral a través de la presentación o recomendación que hace el pariente ya establecido. Es también la red la que permite desplazarse entre distintos lugares e ir sorteando las épocas de desempleo. La red oficia así de mediación entre el migrante y el mercado laboral, constituyendo como se ha planteado (Hily et al. 2004) un mecanismo de interacción con la comunidad receptora.

Los parientes daban el primer alojamiento, elemento de suma importancia, máxime en un poblado con escasez de viviendas y clima riguroso, así como asistencia durante los primeros tiempos. En el caso de Tomás, se trató de un galponcito -usado eventualmente de gallinero- que sus parientes le habilitan para poder dormir a su llegada a Ushuaia. En el caso de Francisco, ya hemos visto que su tío lo alojó en Comodoro Rivadavia pero, antes de eso, cuando llega junto a su madre y dos hermanos más a Ushuaia, es su hermana mayor -ya instaladala que les facilita el lugar donde quedarse:

No había dónde vivir. Cuando yo llegué acá, una pieza así [señala], yo viví adonde está la iglesia de los mormones, ahi habia un corte de tierra, ahí vivía mi hermana... hacía quinta mi hermana, en este lugar guardaban las papas debajo de la viruta, la madera, donde trabajaban. Cuando llegamos nosotros se sacó todo, se pusieron una cucheta ahí, otra arriba, otra allá, otra arriba, mi mamá dormía debajo en esa cucheta, y nosotros de ahí, arriba y de ahí, arriba, así todos encerraditos en una piecita así como ésta (Francisco, llegado a Ushuaia en 1952).

Una observación que se desprende de los distintos testimonios: en los relatos de migración aparecen involucrados esencialmente parientes directos como hermanos, padres, hijos, tíos y eventualmente primos. En un único caso se hizo referencia a un padrino del entrevistado (una figura igualmente asimilada a la familia) como aquel que transmitió información sobre el destino, pero en la mayor parte de los casos relevados las vinculaciones se establecen entre familiares muy cercanos. $\mathrm{Si}$, como sugieren algunos autores (Pedone, 2010), le llamamos cadena migratoria a la porción de la red más directamente involucrada en la concreción del viaje del migrante, veremos cuán estrictamente familiares son estas cadenas, involucrando siempre a parientes directos $y$, por otro lado, cuán extendidas están en el espacio, abarcando distintos destinos patagónicos. Aquí tomaremos algunos aspectos muy someros de esta cuestión en función, principalmente, de las migraciones de mujeres pero resta por hacer una indagación más profunda de estas estructuras familiares que operan a la distancia asegurando la reproducción familiar.

\section{Mujeres migrantes}

Las migraciones de mujeres tuvieron algunas características particulares. Ya hemos señalado la alta tasa de masculinidad que caracterizaba a Ushuaia y a toda Tierra del Fuego. Desde la perspectiva de los hombres la situación se describía así:

cuando me casé... capaz que te quedabas sin mujer en esa época, estaban los... (gesto) buitres, [...] en esa época era peligroso, algunos compañeros de trabajo se quedaron sin mujer..

P: ¿Había pocas mujeres?

$R$ : Pocas, la juventud tenía que caer en esos barrios, piringundines, que eran escasos también (Enrique, llegado a Ushuaia en 1947).

En muchos casos, especialmente en las 
décadas del '40 y '50 los hombres volvían a Chile a buscar mujeres para formar familia y radicarse definitivamente en Ushuaia. Algunos volvían a Chiloé y allí buscaban entre sus antiguos vecinos y allegados una candidata con la que retornaban a Tierra del Fuego. Otros la encontraban en Punta Arenas, como el caso del mismo Enrique, quien había conocido fugazmente a su futura esposa en el barco que los traía a ambos desde Puerto Montt a Punta Arenas, luego la vuelve a encontrar cuando, ya radicado en Ushuaia, debe viajar a Punta Arenas a cumplir con el servicio militar y finalmente vuelve alli en el '53 a proponerle matrimonio. En estos casos las mujeres constituyen una migración vinculada a la intención de los hombres de establecerse en la zona. Encontramos aquí también el llamado pero esta vez para casarse, constituir un hogar y establecerse definitivamente. En muchos casos estas mujeres se convertían en amas de casa sin integrarse al mercado de trabajo formal, aunque veremos, más adelante, algunas peculiaridades de esta situación. Algo semejante acontecía con las mujeres que vinieron junto con marido e hijos, es decir, como integrantes del entero grupo familiar que se desplazaba. Esto solía ocurrir, frecuentemente, un tiempo después, una vez que el marido había encontrado trabajo y decidía establecerse en la zona.

Sin embargo, no todas las mujeres llegaron traídas por sus maridos. En otros casos la red familiar, aunque dispersa a lo largo de miles de kilómetros, seguía haciéndose cargo de aquellos miembros que quedaban desprotegidos como solía ocurrir con viudas y huérfanos/as. El caso de Mary, que llegó en 1960 a Río Grande con 9 años de edad, es ilustrativo. Ella había sido criada, en Chiloé, por su abuela. Cuando ésta está a punto de morir, llama a todos sus hijos y le indica a una que se haga cargo de la niña. Esta hija, tía de la niña, vivía ya en Río Grande y se la lleva consigo. Otro caso: Rosa vivía en Punta Arenas, cuando a sus doce años, muere su padre; la madre viuda recibió, entonces, sendas invitaciones de dos de sus hermanas para reunirse con ellas; una estaba radicada en las islas Malvinas y la otra en Ushuaia. Rosa y su madre optaron, finalmente, por este último destino a donde se dirigirían en 1952. Una variante de esta situación es la de las madres que vienen o son traídas por los hijos cuando éstos logran insertarse y tener un empleo estable.

Pero también encontramos mujeres jóvenes y solteras que vinieron a vivir a casa de sus hermanos previamente radicados en la zona. Es el caso de Delia, que había crecido en Chiloé pero pasó unos años en Santiago de Chile antes de llegar a Tierra del Fuego.

Tenía un hermano en Río Grande, trabajaba en YPF, y él me llamó que vaya a conocer [...] mi hermano estaba casado ahí y yo me quedé. Me dice: bueno, que acá es mejor, que acá esto. Sí, las cosas eran re baratas ese tiempo, '63... (Delia, llegada a Ushuaia en 1965).

A diferencia de las migraciones de hombres, en los movimientos de mujeres encontramos una trama más cerrada, de parientes más cercanos (hermanos, hijos, tíos), que recibe a la mujer en el destino. Relevamos un solo caso de una joven que se había trasladado de Punta Arenas a Ushuaia a instancias de una mujer que la emplearía en su casa como servicio doméstico. Sin embargo, se pudo observar que la decisión de trasladarse se terminó de tomar gracias a que la muchacha contaba con una tía en Ushuaia, que de hecho la recibió, un mes después, cuando se retiró de la casa de su patrona al no prosperar la relación laboral. Al año siguiente, la madre de la joven, junto con dos de sus hermanitos se vendrían de Punta Arenas a instalarse también -temporalmente- en casa de aquella misma tía. Las mujeres se integraban, por lo general, al hogar del pariente que las recibía y se quedaban alli hasta que eventualmente se casaban o juntaban. Cabe destacar que esto ocurría muy rápidamente: en una sociedad con una tasa de masculinidad tan alta, viudas y solteras se encontraban inmediatamente con propuestas de emparejamiento.

\section{USHUAIA: LAS POLÍTICAS DE POBLAMIENTO}

\section{La Patagonia austral}

¿Por qué llegar hasta Ushuaia? ¿Qué podía ofrecer este pequeño poblado un poco apartado que revestía como capital de la gobernación de la Tierra del Fuego argentina? Recordemos en primer término que quienes llegaron y se establecieron en 
Ushuaia, lo hicieron como un segundo o tercer movimiento desde otro punto de la Patagonia austral. Es decir que la primera atracción la había producido otro lugar distinto a Ushuaia. La cuestión es importante porque trataremos de mostrar que las acciones desarrolladas por el Estado argentino para atraer pobladores tuvieron éxito principalmente entre quienes ya habían migrado a la región. Desarrollaremos muy brevemente las características económicas de la región en la que se encontraba inserta Ushuaia y, luego, con más detalle, las características particulares de esta pequeña localidad.

Ushuaia se encontraba -desde su fundación en 1884- en la trama de una amplia área económica que comprendía, además de los sectores argentino y chileno de la isla de Tierra del Fuego, toda el área magallánica chilena, la Patagonia sur argentina y las islas Malvinas. Desde fines del siglo XIX, todas estas regiones se articulaban entre sí y con el mercado internacional (Luiz \& Schillat, 1998; Bascopé, 2008). La principal actividad económica de la región había sido la producción ovina destinada a la exportación de lana y de carne. Ligada a ella operaron también algunos frigoríficos importantes. Mientras la producción se localizaba en las grandes estancias de toda la región, el centro económico y financiero, así como el puerto más importante, estaban en la ciudad chilena de Punta Arenas. Desde allí se embarcaba la lana y la carne y alli se cerraban los negocios que involucraban la producción tanto de las estancias chilenas como argentinas, algunas de las cuales pertenecían a las mismas compañías que operaban a uno y otro lado de la frontera (Martinic, 2002; Bascopé, 2008).

La exportación de lana tuvo un declive después de la Primera Guerra Mundial pero siguió siendo la actividad predominante en toda la región. La crisis del '30 también la afectó negativamente al cerrarse los mercados externos para los productos de exportación como la lana, lo mismo que para la carne, madera y otros, que eran la columna vertebral de la economía magallánica. Las décadas del '20 al '50 fueron de discreta declinación: a las crisis siguieron algunas reactivaciones que nunca lograron hacer volver a la región al esplendor de principios de siglo (Martinic, 2002).

Más allá de sus altibajos, el tipo de desarrollo económico que se fue desplegando explica la atracción que podía ejercer la región para miles de trabajadores. Muy diezmada la población aborigen, las estancias pronto requirieron mano de obra que provino primero de Europa -especialmente a fines del siglo XIX y durante las primeras décadas del XX- y luego también de otras regiones de Chile y Argentina. Lo mismo ocurría con los frigoríficos y con el puerto, dos ámbitos que también demandaban trabajadores. Se trataba de una economía agroindustrial bien desarrollada que ofrecía salarios en dinero y resultaba un polo de atracción tanto para los migrantes transnacionales como para las personas que provenían de las regiones interiores -argentinas y chilenas pero de estas últimas en mayor proporción- en las que predominaba una economía de autoconsumo (Lausic, 2005).

El éxito de este desarrollo podía medirse por el tamaño que iba adquiriendo Punta Arenas, su ciudad principal: el censo de 1906 organizado por la Junta de Alcaldes de Magallanes señalaba la presencia de 13.000 habitantes, una cuarta parte de ellos, extranjeros (mayoritariamente europeos), y tres cuartas partes de otras regiones chilenas, en su mayoría de Chiloé (Lausic, 2005). No obstante los periodos de retracción económica y declinación del comercio de la lana, la población de Punta Arenas continuó creciendo y recibiendo migrantes, ahora predominantemente de otras regiones chilenas. Hacia 1950 la ciudad contaba con unos 50.000 habitantes (Martinic, 2002), es decir, 25 veces la población de Ushuaia para esa misma fecha.

En síntesis, la región se caracterizó por una economía capitalista dinámica y orientada al mercado mundial que atrajo a numerosos trabajadores. El desarrollo de una economía de este tipo había sido impulsado por los Estados de Chile y Argentina con el objeto de ocupar y poblar los territorios que incorporaban a su órbita, a través de algunas medidas como la de conceder grandes extensiones de tierra a las compañías que pudieran asegurar rápidamente la ocupación de las mismas. Esta política, llevada adelante por ambos Estados, que orientaba decididamente la economía hacia la exportación de materias primas y consolidaba el latifundio, le dio a la región su primera configuración (Luiz \& Schillat, 1998; Bandieri, 2005).

A partir de la década del '30 el Estado argentino desplegó algunas políticas 
intervencionistas que buscaban una adecuación a las nuevas condiciones que ofrecía el escenario económico internacional. Una política de sustitución de importaciones y de impulso a la industria y al mercado interno se fue afianzando a lo largo de las décadas centrales del siglo XX. Un componente de esa política, con importantes consecuencias para la región patagónica, fue la preocupación por alcanzar el autoabastecimiento energético. Ello generó proyectos de explotación gasífera y petrolera, que recibieron, especialmente a partir de 1958, bajo la presidencia de Frondizi, un fuerte impulso. Por otro lado, se incrementaron las barreras comerciales y se ejerció un mayor control aduanero entre Chile y Argentina, situación que afectó negativamente, en mayor medida, a la Patagonia chilena (Navarro Floria, 1999; Torres, 2001).

\section{El Estado argentino \\ y la colonización del extremo sur}

Ushuaia había sido fundada, a fines del siglo XIX, en el emplazamiento donde se hallaba una misión anglicana de origen inglés y respondía al propósito de fortalecer la soberanía argentina tanto frente a Chile como frente a Gran Bretaña en el Canal de Beagle. Estaba situada en una zona montañosa y por lo tanto un poco al margen de la actividad ganadera más propia de las zonas de estepa. Requirió, en consecuencia, otro tipo de fomento para establecer allí una población permanente y el Estado nacional debió implicarse más directamente. Se optó por la instalación de una colonia penal que devino finalmente una cárcel común. Este Presidio y Cárcel de Reincidentes fue durante muchos años la institución central del poblado de Ushuaia. Su imponente edificio, que comenzó a construirse en 1902, así como sus autoridades, sus empleados y sus rutinas, constituyeron la presencia más tangible del Estado argentino en la zona. El establecimiento había sido pensado, desde la lejana capital de la república, como herramienta para poblar la región y asegurar su ocupación. Ese propósito ya había sido claramente enunciado, años antes, por el Presidente Roca al presentar al Congreso, en 1883, un proyecto de colonia penal: Una vez fundado el establecimiento Penal en Tierra del Fuego, la República habrá puesto los cimientos de la colonización en ese punto (citado en Caimari, 2000).

$\mathrm{Y}$ efectivamente, cuando finalmente se puso en funcionamiento, el Presidio se constituyó en el principal proveedor de empleos de la zona. Pero, además, el alto número de presidiarios que albergaba constituía la mano de obra para los trabajos de construcción y mantenimiento de calles y edificios públicos que el pequeño poblado necesitaba. En su interior, se fueron conformando talleres en los que los penados producían una variedad de bienes y servicios como la electricidad, muebles de madera o el pan. A lo largo de varias décadas se fue estableciendo, alrededor de la cárcel, una pequeña población que dependía de ella para su subsistencia (García Basalo, 1984; Caimari, 2000; Cecarelli, 2011).

Esta situación se prolongó hasta el año 1947 en que un decreto del Presidente Perón dispuso la clausura del penal y el traspaso de sus instalaciones al Ministerio de Marina. El cierre del penal produjo un cierto éxodo de habitantes: en primer lugar, el de la mayoría de los penados, que fueron trasladados a otros establecimientos. Luego, los guardiacárceles y demás empleados con sus familias, que también fueron reubicados en nuevos puestos de trabajo en otros lugares del país. Una mujer, niña entonces, recuerda haber perdido a muchos de sus compañeros de escuela, hijos de los empleados que debían marcharse (Victoria, nacida en Ushuaia en 1934). Unos pocos empleados y algunos presos con condenas prácticamente concluidas optaron por quedarse.

Si el Presidio había sido el agente a través del cual el Estado nacional impulsó el poblamiento de la zona, con su cierre se hacía necesario que una nueva institución tomara el relevo de esa misma tarea.

\section{La Base Naval}

Unos años antes del cierre del Presidio se había creado la Gobernación Marítima de Tierra del Fuego y se había establecido que dicha gobernación sería ejercida por un oficial superior de la Marina de Guerra. Ello colocó al territorio bajo la órbita de la Armada Argentina. Según lo ha sostenido de Imaz (1972) el periodo inaugurado en 1943 con la Gobernación Marítima correspondió a una 
implicación activa del sector público en el desarrollo del territorio, materializada en la inversión pública en infraestructura urbana, instalación de servicios, infraestructura para el turismo y la hotelería, etc. Esta política fue tomando cuerpo a partir de 1947 con la creación de la Estación Aeronaval de Ushuaia y el establecimiento de algunos vuelos regulares que aseguraban las comunicaciones con el continente. En 1950 la Estación se transformó en Base Naval Ushuaia (Lonzieme, 1984). Fue esta Base la que ofició, como antes lo había hecho el Presidio, de motor de la pequeña ciudad.

La preocupación por radicar industrias y población a orillas del Canal de Beagle tuvo varias expresiones. Una de ellas ocurrió en 1948 cuando el presidente Perón facultó al Ministerio de Marina a desarrollar un plan de fomento $y$ desarrollo industrial que consistía en créditos para construir plantas fabriles, adjudicación de tierras fiscales y concesión de monopolios para explotar determinada industria. Pese a la generosidad de las condiciones que otorgaba no llegó a tener mucho efecto. Durante aquel mismo año también se firmó un contrato con la firma italiana Borsari para la realización de obras públicas. En el marco del acuerdo, el Estado argentino pagó los pasajes de aproximadamente unos 1.000 técnicos y obreros que vendrían del norte de Italia a instalarse en Ushuaia (Mastroscello, 2009). Recuérdese que la población apenas sobrepasaba las 2.000 personas para calibrar la magnitud de este movimiento que le agregaría casi un $50 \%$ más de población. Aunque la firma instaló una fábrica de terciados y los empleados levantaron dos barrios completos en la pequeña localidad, al cabo de poco tiempo la fábrica cerró y la mayoría de los italianos retornó a Italia o partió a instalarse en otras regiones de la Argentina.

Pero indudablemente, la Marina había asumido un rol importante en la generación de obra pública, tanto para instalaciones militares como para crear o reforzar infraestructura urbana. Puede observarse también que los intentos de atraer población se orientaban a la tradicional migración ultramarina y europea, como lo muestra el acuerdo con la firma Borsari, o a población argentina que se revelaba más difícil de atraer en forma permanente. En ese resquicio de fomento de obra pública $y$ de dificultades para atraer población argentina o europea, encontraron lugar los migrantes chilenos que circulaban por la región.

\section{LA DEMANDA LABORAL EN USHUAIA}

¿A qué tipo de trabajo podía aspirar un migrante en Ushuaia? Empezaremos con las posibilidades que encontraban los hombres. La demanda de mano de obra no calificada giraba, por lo general, alrededor de trabajos rurales como el de hachero, boyero, etc, en los bosques de alrededor de Ushuaia para proveer de madera a los aserraderos y abastecer las necesidades de calefacción del poblado. Otra inserción posible, vinculada a la actividad anterior, era el trabajo en los aserraderos. Se trataba en ambos casos de ocupaciones rurales o semi-rurales similares a las que ofrecían las estancias y que continuaban el tipo de migración rural-rural propio de las primeras décadas del siglo XX (Torres, 2001).

Pero, indudablemente, la mayor demanda de mano de obra no calificada fue para la construcción de infraestructura urbana. Hasta el año 1947 en que cerró el Presidio de Ushuaia, eran los presos quienes realizaban este tipo de trabajos pero, a partir de allí, hubo que reemplazar esa mano de obra por personal contratado. Por otro lado, como ya habíamos señalado, la Base Naval impulsó algunas obras urbanas de bastante envergadura como barrios, aeropuerto, etc. Como lo describe Tomás al llegar a Ushuaia en el año 1948: En ese tiempo estaban las construcciones, mucho trabajo había de construcciones acá, las calles, el Solier [barrio de Ushuaia], las zanjas para instalar el agua, todas esas cosas. Se trataba también de trabajos al aire libre, tan duros como los rurales, pero con la posibilidad de algunas ventajas que podía dar el medio urbano. El barrio Solier que describe el entrevistado es el que construyó la firma Borsari, lo que señalaría que la demanda de mano de obra excedía lo que podían cubrir los italianos.

La Base Naval generó también una demanda de trabajadores con oficios: maquinistas, carpinteros, electricistas, etc. En el siguiente testimonio el entrevistado relata la inserción laboral de su tío en 1948 y la de su padre en el año 1950:

Mi tío era maquinista de la usina, de la usina de la Base Naval, la que daba 
luz al pueblo. .. Mi tío había venido en el año ' $48, \ldots$ a él le ofrecieron el trabajo de maquinista... él fue maquinista de la Armada [chilena], en los buques. Le dijeron: mirá, ahí hay unos motores muy similares a los que usan los buques, así que si te interesa el trabajo..., el tipo era muy profesional en sus trabajos, asi que anduvo muy bien, y le gustó, se quedó, trajo a mi tía, a sus chicos... Ellos también venían de Punta Arenas.

[refiriéndose a su padre] ...porque resulta que lo vinieron a buscar de la Base, había un Comandante que quería renovar los muebles y le dijeron que había un carpintero muy bueno, de Punta Arenas. Y bueno, lo vinieron a ver y fue [...] Asi que de entrada mi viejo tuvo trabajo, y de entrada, cuando él terminó los muebles, como a él le prestaron las máquinas de adentro de Marina, fue más rápido. entonces, no, no lo dejaron salir más... y se jubiló ahí (Carlos A

., llegado a Ushuaia en 1950).

Nótese el detalle de que tanto el tío como el padre pertenecían a las fuerzas armadas chilenas $y$ estaban en actividad cuando los tentaron para radicarse en Ushuaia, en sendas visitas a la ciudad. El paso de una fuerza armada a la otra no parecía suscitar ninguna objeción o prurito. Estos puestos fueron ocupados prácticamente en su totalidad por chilenos como lo señala el mismo entrevistado en otro segmento de la entrevista:

...Talleres Generales la mayoría, eran todos chilenos, mi viejo era un chileno más. [...] Y los militares argentinos no tomaban en cuenta eso de que era un chileno; y ¿cómo? ¿adentro de una Base Naval? No, para nada. Como nosotros... pasaron los años, yo entré a Vialidad Nacional y en Vialidad Nacional el 90\% éramos todos chilenos (Carlos A., llegado a Ushuaia en 1950).

La otra institución nacional que incorporó a numerosos trabajadores fue, como se menciona en la cita, Vialidad Nacional. Fueron necesarios especialmente para realizar algunas obras de cierta envergadura como el trazado de la actual ruta nacional $n^{\circ} 3$, que uniría las ciudades de Ushuaia y Río Grande a través de la cordillera de los Andes, una obra importante que empleó tanto a trabajadores no calificados para el trabajo en terreno, como a choferes y personal técnico en los talleres. Tal como aparece consignado en el testimonio, no solamente el personal técnico sino también el no calificado eran, prácticamente en su totalidad, de origen chileno. El empleo en las oficinas administrativas del Estado también fue una posibilidad para unos pocos jóvenes que lograron entrar como personal de maestranza en las distintas reparticiones públicas, pudiendo algunos hacer el paso, más adelante, a tareas administrativas o técnicas.

Empecé, te cuento la verdad, sirviendo café, limpiando las oficinas. Seguí, seguí, dibujaba los planos que hacian los dibujantes, ya me fueron haciendo una mesa, con un fieltro arriba [explica el procedimiento de copia de los planos]... soy pionero en la copia heliográfica (Enrique, llegado a Ushuaia en 1947).

A partir de 1958 se registraría todavía un mayor dinamismo en la demanda de mano de obra a partir del impulso que significó la concesión de explotaciones petroleras en la zona de Río Grande, al norte de la isla. Además de dinamizar directamente la economía de la zona con algunas obras y contrataciones de personal, la explotación petrolífera generó regalías que le permitieron al Estado emprender obras de mayor envergadura a lo largo de toda la década del '60. Ello se tradujo, en Ushuaia, en la construcción de hoteles y hosterías con los que se buscaba impulsar el turismo, además de un hospital, un canal de televisión y de diversas obras de infraestructura urbana como pavimentado de calles y redes de distribución domiciliaria de gas. Todas estas construcciones significarían una sostenida demanda de mano de obra.

\section{Mujeres y trabajo}

Retomemos aquí algo de lo planteado al referirnos a la migración femenina. Según se 
desprende de los casos analizados, la migración de las mujeres chilenas podría corresponderse con la caracterización de migración de reunificación familiar. Es decir, las mujeres migrarían para reunirse con sus maridos/familias una vez que aquellos se instalan definitivamente en la zona. Este tipo de movimiento es el que se ha postulado clásicamente, en los estudios migratorios, como correspondiente a las mujeres frente a una migración masculina más vinculada a las oportunidades y estímulos de los mercados laborales. Aunque corresponde, indudablemente, a una forma de la experiencia histórica, también se ha planteado que devino en una perspectiva de análisis que asimiló rápidamente el término migrante al varón que migra en busca de trabajo y se mueve atraído por las posibilidades de nuevos mercados laborales y redujo el papel de las mujeres migrantes a un componente dependiente del primero y más ligado al ámbito de la reproducción y lo doméstico. Esta perspectiva, -mayoritaria en los estudios migratorios hasta 1970 aproximadamente- habría opacado algunos fenómenos como, por ejemplo, las múltiples formas en las que las mujeres han migrado, muchas de ellas solas y en busca de trabajo. También, habría obturado la posibilidad de ver a las mujeres como componentes activos $e$ ineludibles de estrategias familiares de migración $y$, por otro lado, de considerar las diversas formas de participación en los mercados de trabajo una vez instaladas en los nuevos destinos (Martínez Pizarro, 2003; Courtis \& Pacecca, 2010; Mallimaci, 2012). La incorporación de la dimensión del género a los estudios migratorios tiene ya un largo recorrido $y$ ha planteado numerosas y complejas relaciones entre migración y género (que no se limitan, por otro lado, sólo a las mujeres) que exceden la muy breve referencia que estamos haciendo aquí. La mención tiene el propósito de llamar la atención sobre un aspecto que queremos resaltar de nuestro caso: la intensa pero invisibilizada participación de las mujeres chilenas en la esfera productiva. En ese sentido, caracterizar la migración femenina como migración familiar no significa dejar de observar su incorporación -en variadas modalidades- al mundo del trabajo.

Para las mujeres que emigraron a Ushuaia, tanto solas como en familia, había posibilidades de insertarse en el mercado de trabajo aunque en condiciones bastante precarias como solía ser el caso no sólo en esta región. Dos ocupaciones se destacan en el derrotero de las mujeres migrantes según lo que surge de nuestras entrevistas. El más evidente era el servicio doméstico, muy frecuentemente en las casas de las familias de los militares de la Base Naval, que se observa a lo largo de todo el periodo considerado.

Me puse a trabajar en una casa al frente de la Base [..]. ahí había un médico de marina, buena persona, estuve trabajando ahi [...] otro teniente quería que yo fuera a lavarle la ropa a los chicos, a planchar, todas esas cosas, en otra casa era para limpieza, eran tres casas todos tenientes de marina (María Zoila, llegada a Ushuaia en el '49).

...porque trabajaba arriba en la Misión yo ... en los tenientes, capitanes, comandantes, todas esas casas de Misión, [...] Yo me iba a las 9 del día y volvía a las 5, las 6... (Griselda, llegada a Ushuaia en 1952).

...porque te casaste y empezaste a trabajar, en lo que viniese, porque tampoco como ahora, ahora tenés fábricas, esto, lo otro. En casas de familia, casas de militares, así, iba a trabajar, por horas (Delia, llegada a Ushuaia en el '65).

Otra actividad asimilable a ésta era el lavado de ropa que se hacía en la propia casa.

La otra ocupación frecuente era el dar pensión, que podía concretarse en algún establecimiento o, mucho más frecuentemente, en la propia casa familiar que se abría para dar de comer a pensionistas externos. El dar pensión de mesa, es decir preparar y servir comidas, adquiere significación cuando se considera la estructura demográfica que tenía por ese entonces la isla caracterizada por el alto índice de masculinidad que, recordemos, era de 269 hombres por cada 100 mujeres en 1947 disminuyendo progresivamente a 172,8 en 1970. La presencia de trabajadores solos que vivían, eventualmente, en gamelas comunes o alquilaban habitaciones, hacía necesarios los 
servicios de comida así como los de lavado y planchado de ropa.

En el testimonio de Mary aparecen algunos rasgos característicos de esta práctica. Ella empieza a hacer amistad con una mujer que da pensión cuando viene de visita a Ushuaia a visitar a su futuro marido a mediados de la década del ‘ 60 .

\section{P: ¿Ellos eran conocidos de su esposo?}

R: Claro, de mi esposo, porque mi esposo... ellos daban pensión de comer, al mediodía la gente que trabajaba, o a la noche, iban a comer, entonces por ese lado mi esposo llegaba a comer, entonces yo de ahí..., cuando vino mi tía de Río Grande me traía ahí, me iba con mi tía, parábamos ahí y también comíamos.

$P$ : ¿Porque también tenían alojamiento?

$R:$ Claro, alojamiento, sí ....mi esposo no, porque ellos compartian otra casa con sus compañeros. Compartía la comida nada más... en Vialidad?

$P:$ ¿En esa época su esposo trabajaba

R: En Vialidad Nacional, sí....

P: ¿Así que compartía casa pero comía en lo de S...?

$R$ : En lo de S..., sí, pero los días que él estaba porque ellos pasaban más en los campamentos, eran los días de fin de semana, por ahí digamos en el mes

$P$ : Cuénteme un poquito cómo era ese sistema de dar pensión...

R: La pensión era así: porque se acostumbraba, por ejemplo las personas... no había casas de comida, no había nada, entonces las personas, digamos antes, se dedicaban a hacer comidas, hacian el menú, supongamos para 10 personas, más no tenían...

P: ¿Eso se hacía en su propia casa? tenían que arreglar un poco...?

$R$ : En su propia casa, arreglaban y se compraba una cocina más grande, horno para hacer el pan, porque antes solamente era la Base que hacía pan, [...]

$P$ : Y la señora de S..., ¿ella cocinaba?
R: Claro, ella cocinaba, ella trabajaba en las casas del gobernador [...] y después se dedicaba -trabajó mucho esa mujer- se dedicaba a cocinar para la pensión, porque no era fácil la vida de antes, se pagaba muy poco, y no había muchos recursos... (Mary, llegada a Ushuaia en 1967).

Testimonios como éste se repiten en varios casos e ilustran algunas características comunes. Se acondicionaba la propia casa para cocinar en mayor escala y recibir a los pensionistas hasta una cantidad que no solía superar, en general, la decena de personas. La madre de Francisco, por ejemplo, recibía, según su hijo, 7 u 8 personas que dejaban el espacio para dar lugar a otros tantos en un segundo turno de comidas. Era un servicio que aprovechaban, como se ve en el fragmento citado, los trabajadores de Vialidad Nacional pero también distintos trabajadores rurales o urbanos como también señala otra entrevistada, Elena, nacida en Ushuaia en 1954, sobre quienes asistían a la pensión de su madre: los que esquilaban o los que trabajaban en los aserraderos, la gente que hizo la ruta, que hizo el asfalto... o más adelante también los empleados de algunas pequeñas fábricas.

La cocina estaba a cargo de la mujer de la casa $e$, incluso, también parte de la producción de los alimentos: muchas de ellas tenían gallinero y huerta de donde obtenían las papas, nabos, cebollas, zanahorias, etc. que luego usaban para cocinar. Para cubrir la gran cantidad de tareas que requería el dar pensión era necesario también el trabajo de los hijos: Había que lavar, que planchar, que cocinar, yo tenía 8 años y estaba arriba de un banco porque mi mamá daba pensión y alojamiento, había que trabajar, los permisos eran pocos (Elena, nacida en Ushuaia en 1954).

Este servicio estaba muy extendido. Como señala Mary en el fragmento citado, no había casas de comida ni establecimientos comerciales que pudieran abastecer la demanda de estos trabajadores. Las empresas que contrataban a los trabajadores no siempre preveían servicios que respondieran a esta necesidad ni el incipiente mercado lo proveía de forma más formalizada, de manera que era cubierto por estas mujeres desde 
sus propias casas. Sin embargo, es sumamente interesante el hecho de que no aparece en la conciencia de sus protagonistas como un trabajo, quizá por el hecho de realizarse en la propia casa. En el siguiente testimonio se puede apreciar claramente:

\section{P: Acá en Ushuaia ¿trabajó? ¿o fue ama de casa? \\ $R$ : Mi esposo nunca me dejó trabajar, yo ya estaba perdiendo la vista igual, yo tenía 9 años cuando empecé a perder la vista, pero de a poco...}

P: Era ama de casa, ¿entonces...?

$R$ : Ama de casa, a veces también cocinaba para los chicos de la fábrica de Brisighelli, tenía cinco...

$P$ : ¿Como pensionistas?

$R$ : Como pensionistas, sí, iban a almorzar...

$P$ : ¿En su casa?

R: En mi casa, mi casa es la que está en el Barrio Bahía, donde está la usina para acá, el barrio Bahía...

Funcionaba como una extensión de la actividad doméstica y familiar y así era percibida. Se observará que, frente a la pregunta de si ellas trabajaban, la respuesta es no; sólo en un segundo momento se hace referencia a esta ocupación. Funcionaba tanto en el plano práctico como en el simbólico como un espacio intermedio entre lo privado y lo público, entre lo doméstico y lo laboral. Mientras el trabajo como empleada doméstica sí era percibido como trabajo, lo mismo que lavar la ropa, aunque esto fuera hecho en la propia casa, la tarea de dar pensión, no lo era, pese a que podía ser de bastante magnitud.

Otros modos de participación en el mercado salidos del espacio de lo doméstico eran, por ejemplo, la venta de verduras en los almacenes locales. En casi todas las casas se acostumbraba tener una huerta para el consumo familiar pero algunas mujeres producían lo suficiente para vender una parte en los poquitos almacenes que había. Una entrevistada incluso, más adelante y junto con su marido, llegó a venderle lechuga a los barcos de turismo.

Cabe aquí otra reflexión sobre estas ocupaciones que asumían las mujeres chilenas. En casos similares se ha planteado cómo la presencia anterior de migrantes puede constituir un nicho laboral etnicizado en el que las mujeres encuentran ocupación generalmente vinculada a la producción de comidas y servicios para la comunidad (Mallimaci, 2012). De acuerdo con este planteamiento se podría sostener que estamos frente a una respuesta a la demanda que los trabajadores chilenos podían realizar de comidas, servicios y productos que recrearan para ellos un ámbito más familiar, vinculado a las propias tradiciones y a la nostalgia. Aunque esto puede haber jugado un cierto papel, nos parece que la proporción de la población chilena respecto de la población total (recordemos que constituían el 70\% de la población activa en 1947 y el $50 \%$ en 1970) ubica a esta actividad en otro plano de análisis. Por otro lado, la demanda de los servicios de pensión no se limitaba a la población chilena como aparece mencionado en el siguiente testimonio:

P: Te pregunto por la pensión... ¿qué tipo de gente recibía?

R: Todos chilenos. Por ahí había algún correntino...

$P$ : Chilenos, siempre...¿porque eran la mayoría o...?

$R$ : No, no. ¿Y también sabés quienes venían mucho? los soldados de la Base, que ellos venían de Corrientes, de Chaco, ellos venían y mi mamá siempre los albergaba, tenían un lugar donde tomar un café o escuchar música, de eso me acuerdo...

$P$ : Y los chilenos ¿qué hacían?

$R$ : Trabajaban todos... (Elena, nacida en TDF, en 1954).

En ese sentido, sería interesante poder mensurar el aporte a la configuración de un incipiente mercado interno en la ciudad y su papel como sostén de toda una población trabajadora. En ausencia de estudios más precisos, creemos probable que, cualquiera fuera su importancia relativa, queda enmascarado por el hecho de estar a cargo exclusivamente de mujeres y por sus características de espacio intermedio entre lo doméstico y lo laboral. 
Otras inserciones laborales también estuvieron disponibles para las mujeres. Aunque prácticamente no hubo establecimientos de tipo industrial en Ushuaia hasta años después, los pocos que hubo como la fábrica de terciados Borsari, que operó durante unos pocos años, emplearon también a mujeres chilenas y varias de nuestras entrevistadas trabajaron allí ocasionalmente. Sobre el final de los años considerados, es decir en las décadas del '60 y '70, algunas mujeres se fueron incorporando a trabajos administrativos. Ello fue posible a partir del crecimiento de algunas de las agencias estatales -como las oficinas dependientes del gobierno nacional o las de Vialidad Nacionalpero también la instalación de Aerolíneas Argentinas o, más tarde, LADE (Líneas Aéreas del Estado). Estas estructuras administrativas que se ampliaban permitieron el acceso a algunas mujeres - que quizás habían comenzado con algún trabajo de limpiezaa puestos administrativos, mediado eventualmente por el paso por una Academia Pitman donde se podía aprender a escribir a máquina. Sin embargo, y a partir de los testimonios, parece insinuarse que el paso de trabajos menos calificados a empleos de oficina se logró, más frecuentemente, en la generación siguiente, es decir, la de los hijos nacidos ya en Ushuaia. Esta afirmación requeriría, de todas maneras, ser contrastada con otro tipo de análisis.

\section{CONCLUSIONES}

Hemos abordado las características del crecimiento de Ushuaia analizando las características de los flujos migratorios regionales, por un lado, y destacando, por el otro, la acción del Estado como su principal impulsor. La institución que ocupó el lugar del antiguo presidio como motor del crecimiento fue la Base Naval, dependiente de la Marina argentina. Organizó la provisión de algunos servicios públicos como la electricidad, necesarios para el poblado y se constituyó en el principal empleador de la ciudad. Tanto en sus propios talleres como a través de la contratación de terceros para la realización de grandes obras, generó puestos de trabajo que no podían ser cubiertos por la muy escasa población local. Vialidad Nacional hizo otro tanto. Para responder a esta demanda estuvieron prestos muchos chilenos provenientes principalmente de Chiloé y zonas aledañas. Una economía deprimida y poco monetarizada los había impulsado hacia el sur en busca de mejores horizontes. Ese movimiento se había generado por la atracción que las regiones magallánica y patagónica, articuladas entre sí, pujantes y capaces de ofrecer salarios comparativamente mejores, venían ejerciendo desde varias décadas atrás. La perduración de este desequilibrio regional permitió la constitución de flujos migratorios sostenidos en el tiempo y de mecanismos que los sostenían y aceitaban convenientemente. De la articulación entre este flujo de migrantes y algunas políticas específicas de fomento poblacional que encaró el Estado argentino a través, especialmente, de la Base Naval Ushuaia, resultó el crecimiento poblacional de un poblado que, por un lado, se situaba al margen del movimiento económico más importante de la región y, por el otro, no aparecía como suficientemente atractivo para convocar a la radicación de ciudadanos argentinos.

Hemos planteado, en segundo término, el papel clave que las redes migratorias jugaron en esta dinámica. Para chilotes y chilenos del sur en general, la migración fue, durante muchos años, una opción válida para mejorar su calidad de vida. Durante ese tiempo se fueron consolidando amplias redes de ayuda mutua que facilitaban las migraciones y la inserción en los distintos destinos patagónicos. Con la mediación de estas redes migratorias muchos chilenos llegaron a Ushuaia, encontraron trabajo y se radicaron definitivamente. A través de ellas se obtenía información sobre las posibilidades laborales, elemento crucial en un destino pequeño y periférico respecto de otros nodos más importantes como Punta Arenas y se obtenía alojamiento y asistencia en los primeros momentos. De la misma manera servían para ser introducidos y presentados a los posibles empleadores y, dada su extensión en distintos destinos patagónicos, las redes servían también para atenuar los momentos de desempleo en un lugar específico, desplazándose por ella.

Por último, analizamos las posibilidades de inserción laboral en Ushuaia. En lo que refiere a los hombres, éstas estuvieron dadas por algunas ocupaciones vinculadas a la explotación forestal y, en mayor medida, el empleo de baja calificación generado por el Estado: principalmente la 
construcción de infraestructura urbana y la de la red vial nacional. En segundo lugar hubo incorporación, también a empleos estatales, en los rubros técnicos y de oficios: maquinistas, carpinteros, etc. En el caso de las mujeres migrantes, cuantitativamente menor, la llegada a Ushuaia estuvo signada en mayor proporción por las relaciones familiares, es decir, vinieron para reunirse con sus familias, ya fueran maridos, hermanos o hijos. En mucha menor proporción vinieron expresamente en busca de trabajo. Sin embargo, como se vio, esto no significa que no desempeñaran un papel muy relevante en la economía de la ciudad: además del trabajo como empleadas domésticas y en otros rubros de servicios, cubrieron una demanda importante en un contexto de trabajo masculino, en ocasiones temporario, como fue el brindar servicio de comidas. Esta actividad realizada en la propia casa no era, por lo general, percibida como trabajo formal.

El desarrollo de estos temas se realizó a partir del análisis de entrevistas a antiguos pobladores y, más en general, de una metodología cualitativa que bucea en la memoria oral. Creemos que ellas brindan posibilidades interesantísimas y abren la puerta a interrogantes, temas y matices que difícilmente se imaginan o se perciben antes de realizarlas. Pero también presentan limitaciones, especialmente a la hora de ligar los casos particulares con afirmaciones más generales respecto de, por ejemplo, la estructura social. En ese sentido planteamos estas conclusiones como hipótesis a ser contrastadas, complementadas y enriquecidas con otros abordajes. También, ojalá, a ser profundizadas, especialmente las que se refieren al trabajo femenino, un tema que apenas iniciamos.

\section{AGRADECIMIENTOS}

Las entrevistas y parte del trabajo de análisis de las mismas se realizaron en el marco del Proyecto de Archivo de Memoria Oral llevado adelante por la Dirección de Administración y Gestión del Patrimonio Histórico Cultural de la Municipalidad de Ushuaia entre 2014 y 2015. Agradezco a Elizabeth Guevara quien ideó, impulsó y sostuvo el proyecto así como a mis compañeros y partícipes del mismo: Agustín
Coto y Ana Ferreyra. También al resto de mis compañeros de Casa Beban y Casa Pena siempre dispuestos a colaborar en lo que fuera necesario. Una parte del proyecto se realizó en convenio con la UNTDF y en ese marco participaron Peter Van Aert, Mariano Malizia y Gabriela Fernández, a quienes agradezco el intercambio y apoyo permanente.

\section{BIBLIOGRAFÍA}

Arango, J. (2003). La explicación teórica de las migraciones: luz y sombra. En Migración y desarrollo, (1). Recuperado de http://www.redalyc.org/articulo.oa?id=66000102

Bandieri, S. (2005). Historia de la Patagonia. Buenos Aires: Sudamericana.

Bascopé Julio, J. (2008). Pasajeros del poder propietario. La Sociedad Explotadora de Tierra del Fuego y la biopolítica estanciera (1890-1920) Magallania, 36(2), 19-44.

Caimari, L. (2000). Una sociedad nacional-carcelaria en la frontera argentina (Ushuaia, 1883-1947). En Primeras Jornadas de Historia del Delito en la Patagonia, Jornadas llevadas a cabo por GEHiSo y las Facultades de Humanidades y de Derecho y Ciencias Sociales, General Roca.

Carpinetti, N. (2003). Perfil sociodemográfico de los migrantes a Tierra del Fuego en el marco regresivo de la evolución económica provincial. Tesis inédita de Maestría en Demografía Social. Universidad Nacional de Luján: Luján, Argentina.

Cecarelli, S. (2011). El penal fueguino: origen del Estado y la sociedad en la frontera austral argentina. Ushuaia: Utopías.

Ceva, M. (2006). La migración limítrofe hacia la Argentina en larga duración. En A. Grimson \& E. Jelin (Comp.), Migraciones regionales hacia la Argentina: Diferencia, desigualdad y derechos. Buenos Aires: Prometeo.

Courtis, C., \& Pacecca, M. I. (2010). Género y trayectoria migratoria: mujeres migrantes y trabajo doméstico en el Área Metropolitana de Buenos Aires. Papeles de Población, 63, CIEAP/UAEM.

Dirección General de Estadística y Censos. Prov. de Tierra del Fuego (2014). Serie de Análisis Social: Migración y empleo en Tierra del Fuego 3. Ushuaia.

Dirección General de Estadística y Censos (1960). Censo Población Resumen País. Chile

De Imaz, J. L. (1972). Los hombres del confín del mundo. 
Buenos Aires: Eudeba.

De La Calle Ysern, F. (1989). La emigración de Chiloé a la Patagonia chilena. Revista Cultura de \& desde Chiloé, 10.

Farías, A. H., \& López, J. C. (2016). Migración y heterogeneidad estructural en Tierra del Fuego. Un análisis de la desigualdad social asociada a procesos migratorios, 2004 y 2014. En IX Jornadas de Sociología de la UNLP 5 al 7 de diciembre de 2016 Ensenada, Argentina. Universidad Nacional de La Plata.

García Basalo, J. C. (1984). Los establecimientos penales. En A. Canclini (Dir.), Ushuaia 1884-1984: Cien años de una ciudad argentina. Ushuaia: Municipalidad de Ushuaia.

Gobantes, C., Barton, J., Román, A., \& Salazar, A. (2011). Migraciones laborales entre la Isla de Chiloé (Chile) y Patagonia Austral: relaciones históricas y cambios recientes en un espacio transnacional. En P. Núñez (Comp.), Miradas Transcordilleranas: Selección de Trabajos del IX Congreso Argentino Chileno de Estudios Históricos e Integración Cultural. San Carlos de Bariloche: IDyPCa, UNRN - CONICET.

Hermida, M., Malizia, M., \& Van Aert, P. (2013). Ser fueguino. Un estudio sobre migración y construcción de pertenencia. En X Jornadas de Sociología. Facultad de Ciencias Sociales, Universidad de Buenos Aires.

Hily, M. A., Berthomière, W., \& Mihaylova, D. (2004). La notion de "Réseaux sociaux" en migration. Hommes et Migrations 1250, 6-12.

Lattes, A. E. (2007). Esplendor y ocaso de las migraciones internas. En S. Torrado (Comp.), Población y Bienestar en la Argentina del primero al segundo Centenario (pp. 11-45). Buenos Aires, Edhasa.

Lausic, S. (2005). Migraciones del archipiélago de la Isla Grande de Chiloé hacia la Patagonia (Chile-Argentina) y participación en el sindicalismo obrero. Revista de Historia, UDEC, Concepción, Chile.

Liberali, A. M. (1978). Migraciones en la Tierra del Fuego (1947-1977), (Tesis de Licenciatura en Geografía), Universidad de Buenos Aires, Buenos Aires. En: http://www.archivo-chile.com
Lonzieme, E. (1984). La Armada nacional. En Canclini (Ed.), Ushuaia 1884-1984. Cien años de una ciudad argentina. Ushuaia: Municipalidad de Ushuaia.

Luiz, M. T., \& Schillat, M. (1998). Tierra del Fuego: Materiales para el estudio de la Historia Regional. Ushuaia: Fuegia.

Mallimaci Barral, A. I. (2011). Las lógicas de la discriminación. Nuevo Mundo Mundos Nuevos. Nouveaux mondes mondes nouveaux-Novo Mundo Mundos Novos-New world New worlds.

Mallimaci Barral, A. (2012). Moviéndose por la Argentina. Sobre la presencia de bolivianos en Ushuaia. Migraciones Internacionales, 6, 4.

Martínez Pizarro, J. (2003). El mapa migratorio de América Latina y el Caribe, las mujeres y el género CEPAL. Serie Población y Desarrollo, 44. Santiago de Chile, N.U.

Martinic, M. (2002). Breve Historia de Magallanes. Punta Arenas: Ediciones de la Universidad de Magallanes.

Massey, D., \& Aysa-Lastra, M. (2005). Social Capital and International Migration from Latin America. En Expert Group Meeting on International Migration and Development in Latin America and the Caribbean, Mexico City, México.

Mastroscello, M. A. (2009). La economía del fin del mundo. Configuración, evolución y perspectivas económicas de Tierra del Fuego. Recuperado de: www.eumed. net/libros/2009a/474/

Navarro Floria, P. (1999). Historia de la Patagonia. Buenos Aires.

Pedone, C. (2010). Cadenas y redes migratorias: propuesta metodológica para el análisis diacrónico-temporal de los procesos migratorios. Empiria. Revista de metodología de ciencias sociales, 19, 101-132.

Torres, S. (2001). Patagonia austral: 1885-1925. Un caso singular y temprano de integración regional autárquica. En S. Bandieri (Coord.). Cruzando la cordillera, Neuquén, CEHIR, Univ. Del Comahue.

Varela, J. (2015). Configuración de la fuerza laboral en Tierra del Fuego. En XI Jornadas de Sociología, Facultad de Ciencias Sociales, Universidad de Buenos Aires. 
